\title{
POLÍTICAS DE AVALIAÇÃO E QUALIDADE DA EDUCAÇÃO. UMA ANÁLISE CRÍTICA NO CONTEXTO DA AVALIAÇÃO EXTERNA DE ESCOLAS, EM PORTUGAL'
}

\author{
José Augusto Pacheco*
}

Recebido: 5 mar. 2014

Aprovado: 30 maio 2014

*Universidade do Minho, Braga, Portugal. Contato com o autor: E-mail: jpacheco@ie.uminho.pt

Resumo: Com este artigo pretende-se abordar a noção de qualidade, invocando não só as ideias de Lipovestky e Gil, mas também os discursos que são construídos sobre a avaliação institucional. Exploram-se, num primeiro ponto, as lógicas de personificação e de controlo social, entendendo-se a sua presença na avaliação como complementares e, num segundo ponto, a noção de qualidade, com recurso à análise do modelo de avaliação externa de escolas, em implementação na realidade escolar portuguesa. O artigo serve de análise crítica das políticas de partilha de conhecimento, cada vez mais preponderantes na regulação das políticas nacionais e na configuração de modelos de avaliação.

Palavras-chave: Qualidade. Personificação. Controlo social. Avaliação institucional.

\section{EVALUATION POLICIES AND EDUCATIONAL QUALITY. A CRITICAL ANALYSIS IN THE CONTEXT OF EXTERNAL EVALUATION OF SCHOOLS, IN PORTUGAL.}

Abstract: In this article we aim to explore the notion of quality, invoking not only the ideas of Lipovestky and Gil, but also the discourses that are created about institutional evaluation. Firstly, we stress the logics of personification and social control, regarded as complementary in the process of evaluation; secondly, we consider the notion of quality by means of an analysis of the model for school's external evaluation, currently being implemented in the Portuguese educational system. The article acts as a critical analysis of policies borrowing and lending, which are becoming increasingly important in the regulation of national politics and in the structuration of evaluation models.

Key words: Quality. Individualization. Social control. Institutional evaluation.

1 Este trabalho é financiado por Fundos FEDER através do Programa Operacional Fatores de Competitividade - COMPETE e por Fundos Nacionais através da FCT - Fundação para a Ciência e a Tecnologia no âmbito do projeto PTDC/CPE-CED/116674/2010. 


\section{INTRODUÇÃO}

Apesar do peso semântico de certas palavras se desgastarem bem depressa com o tempo, sobretudo quando estão associadas a modas pedagógicas introduzidas através de políticas educacionais, que parecem ser a panaceia de todos os problemas sociais, torna-se necessário reconhecer que o termo qualidade tem perdurado nas últimas décadas. Além disso, aceitar-se-á que o seu significado é cada vez mais influente no contexto transnacional, pois impõe um sistema de regulação, de seguida analisado em função das lógicas de personificação, com recurso a escritos de Lipovestky (2013), e de controlo social, na base da proposta de Gil (2009), bem como a partir do atual modelo de avaliação externa de escolas, em Portugal.

\section{DUAS LÓGICAS E UMA MESMA REALIDADE QUALITATIVA}

Pela leitura de autores pertencentes a diversos campos do conhecimento, desde a política e estudos culturais até à filosofia, sociologia e estudos curriculares, as ideias de Lipovetsky (2013) e Gil (2009) não podem deixar de ser consideradas, caso se pretenda compreender a realidade que existe tanto ao nível de uma cultura-mundo (LIPOVETSKY; SERROY, 2010), quanto de uma identidade do sujeito (GIL, 2009).

Se a globalização, enquanto movimento transnacional de uniformização, tende para a legitimação de políticas de partilha de conhecimento (STEINER-KHAMSI, 2012), instituintes de reformas viajantes, e de um modelo pós-burocrático (MAROY, 2012), rosto visível quer das políticas de avaliação, de accountability e de responsabilização (AFONSO, 2010; PACHECO, 2011a), quer do reforço de uma governança mercantil (FOUCAULT, 2010), de que modo a lógica de personalização, ou individualização, se conjuga com a lógica de um controlo socialdo sujeito?

Cabe ainda explorar, em termos de hipótese de trabalho, se as duas referidas lógicas são antinómicas ou complementares. Qualquer análise sobre estas duas lógicas passa pela consideração da qualidade como termo uniformizante, por um lado, de políticas e práticas educativas e indutor de processos de regulação integrados em contextos diferentes, por outro. $\mathrm{Na}$ busca de um eixo semântico que torne inteligível a preponderância do termo, qualidade confere um significado de avaliação, geralmente traduzido mais numa vertente de certificação do mérito ou valor do que numa vertente de melhoria (KRAIG, 2010; NEVO, 2007). 
Argumentando-se que as duas lógicas são antinómicas, defender-se-á que a lógica de personalização exprime não só a singularidade e a subjetividade do sujeito, na afirmação de uma ideologia pós-niilista, de ausência de valores e referenciais (LIPOVETSKY, 2013), mas também a proclamação do relativismo e a ausência de controlos formais, seja a nível puramente individual, seja no plano estritamente social. Por outro lado, na lógica de controlo social, a avaliação consubstancia-se numa forma concreta de subjetivação, através de "um método universal de identidades necessárias à modernização" (GIL, 2009, p. 25), na medida em que os seus efeitos são diversos, especialmente quando, "o ser homem mede-se pela sua posição nas escalas das performances a que incessantemente é submetido" (p. 52).

Tal lógica de controlo inscreve como princípio determinante da realidade social a ideologia do sujeito-avaliado, isto é, a aceitação de uma lógica de produtividade baseada nos resultados, no desempenho e na estandardização, como analisa Maroy (2012) no modelo pós-burocrático. O descentramento educacional da avaliação nos objetivos tem conduzido, pela força das dinâmicas mercantis da globalização e das suas políticas de reformas viajantes, à radicalidade educacional da avaliação baseada nos resultados, presente nos modelos de avaliação externa e na abordagem curricular centrada nos testes.

Mas como não podem ser consideradas antagónicas, as duas lógicas são formas complementares de análise da realidade social, uma vez que a lógica de controlo identitário tem nos seus pressupostos de legitimação a responsabilização do sujeito através da individualização dos atores, espaços e lugares. Poder-se-á, assim, afirmar que a lógica de controlo social potencializa a lógica de personalização, a partir do momento em que o sujeito se torna cúmplice dos resultados da avaliação, analisados a partir de padrões homogéneos e específicos.

Com efeito, a qualidade educacional será uma realidade inerente mais aos sujeitos pedagógicos, sobretudo pais, alunos, educadores e professores (ARROYO, 2012), do que aos sujeitos políticos, com racionalidades diferentes e conflituantes. A avaliação inscreve-se, desta forma concreta, autoritariamente nas expetativas dos sujeitos, estabelecendo mecanismos próprios que conduzem ao sucesso/insucesso, pois a relação entre as duas funções dominantes da avaliação (ALVES; MACHADO, 2008; NEVO, 2007) constituem a etapa final, mesmo que ao longo do processo a função de melhoria se sobreponha à função de certificação.

No entanto, se a discursividade teórica, ainda que muito fragmentada, na base dos pressupostos de uma cultura pós-moderna, sublinha a lógica de per- 
sonalização, na potenciação máxima do sujeito em si e na sua multiplicidade de práticas possíveis e imaginárias numa sociedade flexível, as práticas sociais enredam-se em teias de controlo cada vez mais estandardizadas e uniformizantes, configurando dispositivos de controlo pela avaliação.

Sendo complementares, porque exaltam, por um lado, o sujeito, alargando o seu individualismo, e proclamam a sua responsabilização e culpabilização, por outro, as lógicas de personalização e de controlo social coexistem de modo flexível, como refere Lipovestky (2013, p. 33): “o indivíduo e o seu direito cada vez mais proclamado de se realizar à parte, de ser livre, [coexiste com] técnicas de controlo social [que] passam a aplicar dispositivos mais sofisticados e humanos".

\section{A QUALIDADE CONTROLADA PELO EXTERNO}

Analisando-se o modelo de avaliação externa de escolas, em Portugal, constata-se que os seus pressupostos reafirmam a coexistência das lógicas de controlo social e de individualização.

Iniciado em 2005, na base da elaboração de um modelo nacional, implementado pela Inspeção-geral de Educação e Ciência (IGEC), o processo de avaliação externa é obrigatória para as escolas dos ensinos básico (elementar) e secundário (médio), cumprindo-se em ciclos de cinco anos e formatado em três parâmetros: i) resultados (académicos, outros resultados educativos e reconhecimento da comunidade académica); ii) prestação do serviço educativo (gestão do currículo, práticas de ensino, práticas de monitorização e avaliação e práticas de inclusão e equidade); iii) liderança e gestão escolar (visão, estratégia e planeamento, gestão dos recursos, desenvolvimento pessoal e organizacional, autoavaliação e melhoria) (PACHECO et al., 2014; IGEC, 2012).

Tanto pelo quadro conceptual que o justifica, se bem que se revele muito pobre em termos teóricos, quanto pelas práticas que o legitimam, o modelo de avaliação externa de escolas torna presente os princípios de responsabilização e de reterritorialização institucional.

Tais princípios funcionam a partir do momento em que cada escola, na busca da garantia da qualidade, assume a capacidade de autorregulação institucional e define estratégias de autoavaliação coercivas, discursivamente legitimadas pela avaliação externa. Por exemplo, pela análise do indicador estatístico dos resultados da avaliação externa, regista-se que, no $1^{\circ}$ ciclo de avaliação (20062011), a capacidade de autoavaliação e melhoria da escola melhorou ao longo dos cinco anos, atingindo mesmo assim, em comparação com os restantes pa- 
râmetros, as classificações mais altas ao nível do suficiente (48\%) e insuficiente (4,5\%) (IGEC, 2011).

Porque toda a avaliação externa tem impacto e produz efeitos, as classificações do $1^{\circ}$ ciclo de avaliação relativas à autoavaliação, e o mesmo poderia ser dito sobre as classificações relacionadas com os resultados, especialmente os que traduzem os valores obtidos em testes nacionais, transformaram-se num indicador estatístico de uma avaliação de controlo social, dentro da autonomia reconhecida, pelo menos em termos normativos, a cada escola.

Dito de outro modo: a avaliação externa, para além de um efeito visível de legitimação discursiva, pois nas escolas a noção de qualidade técnico-racional é facilmente incorporada nos seus documentos, origina um efeito procedimental de realização da autoavaliação, considerando-se mais um efeito de uma lógica externa do que uma necessidade funcional da escola. Mesmo assim, os atores escolares, sobretudo educadores e professores, na base de estudos empíricos realizados, concordam com a afirmação de que a autoavaliação é um procedimento induzido pela obrigatoriedade da avaliação externa e que esta não tem contribuído para a melhoria das práticas escolares e consequentemente para a melhoria qualitativa do sucesso dos alunos (CALDAS, 2012; SANTOS, 2012; FREITAS, 2013). Noutros estudos empíricos, é reconhecido que a avaliação externa tem desempenhado um papel importante na consolidação do processo de autoavaliação (COSTA; PACHECO, 2013).

Um outro controlo social efetivo realizado pela avaliação externa diz respeito à indução de uma abordagem do currículo centrada nos testes, e que é essencialmente definida pela abordagem centrada em resultados e pela abordagem centrada em standards, ou seja,formas de governamentalidade curricular expressas nas práticas quotidianas da educação escolar, cada vez mais inseridas numa lógica empresarial para a educação, em normas concretas para a privatização das escolas e em práticas de mercadorização curricular. Porém, os professores de um estudo empírico revelam que os testes nacionais, para além de ser uma prática valorizada na avaliação externa, não refletem as reais aprendizagens dos alunos (MARQUES; PACHECO, 2013).

Com efeito, a qualidade das escolas, definidas pelo objetivo de reforçar a responsabilização individual e institucional, para além de valorizar a política de proximidade, com a valorização dos contextos, é associada a mecanismos externos de avaliação e à fixação de metas a cumprir, de modo que a abordagem do currículo seja mais valorizada pelos resultados que pelos processos e mais, ainda, pela avaliação externa que pela avaliação interna. 
Neste caso, arquiteta-se um sistema de regulação pelos resultados, mediante procedimentos de competitividade das escolas que têm de comparar-se não só entre si como também a nível nacional, para além de terem de implementar procedimentos de previsão e monitorização de resultados, incrustados numa cultura de avaliação abrangente (PACHECO, 2011a; 2011b).

O que torna mais presentes estas lógicas pós-burocráticas é o tipo de regulação, que passa das regras e procedimentos para os resultados, com reforço dos mecanismos externos de avaliação, ou seja, não se baseia na estandardização de processos, impostos pelas normas, mas sim na estandardização de resultados.

Tudo isto resulta da globalização como processo multifacetado de uniformização, com incidência direta na criação de um diálogo comum sobre as reformas, "tornando aparentemente mais uniforme o currículo a nível mundial" (ANDERSON-LEVITT, 2009, p. 356) e estabelecendo uma estandardização avaliativa centrada na comparabilidade, na competitividade e numa linguagem rigorista.

Em consequência, a estandardização é uma forma concreta de criação nas escolas de um certo grau de uniformidade, de acordo com padrões supranacionais e transacionais, moldados, por exemplo, pela União Europeia, Banco Mundiale Organização para a Cooperação e Desenvolvimento Económico, impondo um conceito de qualidade que se transforma num instrumento pessoal e social de igualização através da eficiência.

Qualidade, igualdade e eficiência constituem os três vértices constitutivos de um triângulo de competitividade que funciona tanto para a lógica individualista pós-moderna, quanto para a lógica de controlo social neoliberal. E voltando-se ao início do texto, não existe uma erosão do termo qualidade, tão só a sua ressignificação no sentido de uma qualidade técnico-racional, de vertente certificativa e administrativa.

\section{EM SÍNTESE}

Qualidade é uma palavra-chave que está bem presente nas políticas de partilha de conhecimento e nas reformas educacionais, sobretudo quando está a causa a avaliação. Pela análise realizada infere-se que o significado de qualidade é construído transnacionalmente, tendo como suporte de argumentação analítica tanto a lógica de personificação, quanto a lógica de controlo social. Pela observação feita a partir da realidade portuguesa, com a invocação do modelo de avaliação externa de escolas, verifica-se que o registo externo da avaliação tende a configurar o registo interno, contribuindo 
para a sobreposição da qualidade-desempenho face à qualidade-melhoria, ou seja, a avaliação institucional tende para a exploração da sua instrumentação certificativa e sumativa.

\section{REFERÊNCIAS}

AFONSO, Almerindo. Um olhar sociológico em torno da accountability em educação. In: ESTEBAN, M. T; AFONSO, A. J. (Org.). Olhares e interfaces. São Paulo: Cortez, 2010. p. 147-170.

ALVES, Maria Palmira; MACHADO, Eusébio André (Org.). Avaliação com sentido(s): contributos e questionamentos. V. N. Famalicão: de Facto, 2008.

ANDERSON-LEVITT, K. Globalization and curriculum. In: F. M. CONNELLY (Ed.). The sage handbook of curriculum and instruction. Los Angeles: Sage, 2009. p. 349-36.

ARROYO, Miguel. Outros sujeitos, outras pedagogias. Petrópolis: Vozes, 2012.

CALDAS, Rosa. Impacto da avaliação externa na escola. Um estudo de caso numa escola do litoral norte. Dissertação (Mestrado). Universidade do Minho, Braga, 2012.

COSTA, Natália; PACHECO, José Augusto. Impacto e efeitos da avaliação externa nas estruturas intermédias de gestão. In: CONGRESSO INTERNACIONAL GALEGO-PORTUGUÊS DE PSICOPEDAGOGIA, 12., 2013. Braga, Portugal. Atas..., Braga: Universidade do Minho, 2013.

FOUCAULT, Michael. Nascimento da biopolítica. Lisboa: Edições 70, 2010.

FREITAS, Sandra. Avaliação externa de escolas. Dissertação (Mestrado) Universidade do Minho, Braga, 2013.

GIL, José. Em busca da identidade. O desnorte. Lisboa: Relógio D’Água, 2009.

IGEC. Avaliação externa das escolas. Avaliar a melhoria e a confiança (2006-2011). Lisboa: IGEC, 2011. 
IGEC. Quadro de referência para a avaliação das escolas. Lisboa: IGEC, 2012.

KRAIG, Cridel. Encyclopedia of curriculum studies. London: Sage, 2010.

LIPOVETSKY, Gilles. A era do vazio. Ensaios sobre o individualismo contemporâneo. Lisboa: Edições 70, 2013.

LIPOVETSKY, Gilles; SERROY, Jean. A cultura-mundo. Resposta a uma sociedade desorientada. Lisboa: Edições 70, 2010.

MAROY, Christian. Towards post-bureaucratic modes of governance. In: STEINER-KHAMSI, G.; WALDOW, F. (Org.). World yearbook of education 2012. Policy borrowing and lending in education. London: Routledge, 2012. p. 62-93.

MARQUES, Micaela; PACHECO, José Augusto. Avaliação externa de escolas e seus efeitos nas perspetivas curriculares e pedagógicas. Um estudo com professores de matemática. In CONGRESSO INTERNACIONAL GALEGO-PORTUGUÊS DE PSICOPEDAGOGIA, 12., 2013. Braga, Portugal. Atas..., Braga: Universidade do Minho, 2013.

NEVO, David. Evaluation in Education. In: SHAW, I. F.; GREENE, J. C.; MARK, M. M. (Org.). Handbook of evaluation. Policies, programs and practices. London: Sage Publications, 2007. p. 440-460.

PACHECO, José Augusto et al. Avaliação externa. Para a referencialização de um quadro teórico sobre o impacto e efeitos nas escolas do ensino não superior. Porto: Porto Editora, 2014. p. 7-45.

PACHECO, José Augusto. Discursos e lugares das competências em contextos de educação e formação. Porto: Porto Editora, 2011a.

PACHECO, José Augusto. Currículo, aprendizagem e avaliação. Uma abordagem face à agenda globalizada. Revista Lusófona de Educação, Lisboa, n. 17, p. 65-74, 2011b. Disponível em: $<$ http://revistas.ulusofona.pt/ index.php/rleducacao/article/view/2366>. Acesso em: 3 dez. 2012.

SANTOS, Sandra. Rankings das escolas e qualidade das aprendizagens. Que relação? Um estudo exploratório no ensino privado. Dissertação (Mestrado) - Universidade do Minho: Braga, 2012. 
POLÍTICAS DE AVALIAÇÃO E QUALIDADE DA EDUCAÇÃO. UMA ANÁLISE CRÍTICA NO CONTEXTO DA AVALIAÇÃO EXTERNA DE ESCOLAS, EM PORTUGAL

STEINER-KHAMSI, G. Understanding policy borrowing and lending. Building comparative policy studies. In: STEINER-KHAMSI, G.; WALDOW, F. (Org.). World yearbook of education 2012. Policy borrowing and lending in education. London: Routledge, 2012. p. 5-17. 